\title{
Status Epilepticus: A Review, With Emphasis on Refractory Cases
}

\author{
Gary Hunter, G. Bryan Young
}

\begin{abstract}
Status epilepticus is among the most dramatic of clinical presentations encountered by emergency room physicians, neurologists, neurosurgeons and intensivists. While progress in its management has been aided significantly with an increasing number of effective treatment options, improved diagnostic methods and more effective monitoring, poor outcomes and diagnostic failures are still frequently encountered. Refractory cases still carry significant morbidity and mortality rates, including poor cognitive outcomes. This review discusses basic pathophysiology and management of status epilepticus, neuroimaging findings, the role of continuous electroencephalogram monitoring and nonconvulsive status epilepticusas well as recent developments in treatment options for refractory cases.
\end{abstract}

\begin{abstract}
RÉSUMÉ: Revue sur le status épilepticus avec emphase sur les cas réfractaires au traitement. Le status épilepticus est l'un des tableaux cliniques les plus dramatiques auxquels doivent faire face les urgentologues, les neurologues, les neurochirurgiens et les intensivistes. Bien qu'un nombre croissant d'options efficaces de traitement, de meilleures méthodes diagnostiques et de surveillance en aient amélioré significativement le traitement, les résultats médiocres et les diagnostic erronés sont encore fréquents. Chez les cas réfractaires au traitement, les taux de morbidité et de mortalité demeurent élevés, entre autres pour les conséquences sur la cognition. Cette revue discute de la physiopathologie et de la prise en charge de base du status épilepticus, des observations à la neuroimagerie, du rôle de la surveillance EEG continue, du status epilepticus non convulsif et des développements récents dans les options de traitement pour les cas réfractaires.
\end{abstract}

Can J Neurol Sci. 2012; 39: 157-169

The original definition of status epilepticus was "A condition characterized by an epileptic seizure which is so frequently repeated or so prolonged as to create a fixed and lasting epileptic condition" ". Although this definition is imprecise, it introduces the concept that the normal inhibitory mechanisms of the brain have failed, and that epileptic activity has become selfsustaining, leading to a significantly increased risk for permanent brain injury. The duration criterion was formalized by the International League Against Epilepsy (ILAE) and the Epilepsy Foundation of America (1993), as at least 30 minutes of continuous seizures or sequential seizures without intervening recovery. This time frame is supported by studies on animals that show neuronal death occurring after 30 minutes of continuous convulsive seizure activity, even in absence of physiologic compromise (baboons were paralysed and intubated, with glycaemia normalized $)^{2}$. DeLorenzo and colleagues $^{3}$ have shown that, among patients with prolonged seizures (more than ten minutes), $57 \%$ will progress to true status epilepticus without medication administration. In addition, mortality increases to $19 \%$ for seizures lasting more than 30 minutes, as compared to $2.6 \%$ for those lasting between 10 and 29 minutes. An even more conservative time cut-off was suggested when a video electroencephalogram (EEG) study of 120 secondarily generalized seizures recorded from 47 patients found that none lasted longer than two minutes (mean duration was 62 seconds), suggesting that even five minutes of seizure activity represents a significant deviation from the mean and justifies aggressive treatment ${ }^{4}$. While 30 minutes is a useful cut-off in terms of defining physiological changes, the above points support recent trends towards more aggressive treatment of much briefer seizures.

Embedded within the definition of status epilepticus is the definition of seizure itself. Electrographically, this definition includes an evolutionary pattern of epileptiform discharges followed by post-ictal slowing or suppression, although these criteria may not always apply in prolonged seizures. Using animal models and human cases, Treiman and colleagues ${ }^{5}$ have defined five sequential electrographic stages when status epilepticus persists (Table 1), progressing from intermittent seizures without recovery, then becoming more continuous, and

From the Department of Neurology (GH), University of Saskatchewan, Saskatoon, Saskatchewan; Department of Clinical Neurological Sciences (GBY), University of Western Ontario, London, Ontario, Canada.

Received January 10, 2011. Final Revisions Submitted SePtember 14, 2011. Correspondence to: Gary Hunter, 112, 3502 Taylor St E, Saskatoon, Saskatchewan, S7H 5H9, Canada. 
Table 1: Stages of status Epilepticus ${ }^{5}$

\begin{tabular}{l|l}
\hline Stage 1 & Discrete seizures \\
\hline Stage 2 & $\begin{array}{l}\text { Merging seizures with waxing and waning amplitudes and } \\
\text { frequencies }\end{array}$ \\
\hline Stage 3 & Continuous ictal activity \\
\hline Stage 4 & Continuous ictal activity interrupted by flat periods \\
\hline Stage 5 & Generalized periodic complexes on a flat background \\
\hline
\end{tabular}

culminating in generalized periodic epileptiform discharges (GPEDs) on a suppressed background. With protracted seizures, the variation in EEG over time may become limited, such that the usual criteria of evolution over time does not always apply in the case of status epilepticus, where self-sustaining ictal discharges may appear monotonous on the EEG with minimal variability in frequency, amplitude, or morphology. Individual stages from Treiman's classification may persist for long periods of time as periodic discharges or rhythmic slowing, blurring the distinction between ictal and interictal activity. This becomes especially problematic in comatose patients with mainly nonconvulsive seizures, where suppression of these poorly defined discharges is the only available therapeutic target ${ }^{6}$.

\section{Classification of Status Epilepticus}

Virtually any seizure type from the ILAE classification can be seen as status epilepticus (Table 2). Although one can broadly categorize prolonged seizures as convulsive or non-convulsive, many patients show both clinical and isolated electrographic seizure patterns as a result of status epilepticus. In fact, many "nonconvulsive" cases show subtle signs of seizure activity such as nystagmus, gaze deviation, or low amplitude twitching of the face or limbs. Rarely, autonomic dysfunction can be the primary ictal semiology of nonconvulsive seizures, including either sympathetic or parasympathetic effects, or both simultaneously ${ }^{7,8}$. These changes are probably under-recognized, largely because they are difficult to prove as ictal phenomena, and are less dramatic clinical events than convulsions. The most commonly encountered autonomic manifestations are sympathetic activity such as pupillary dilation and changes in heart rate and blood pressure, whereas parasympathetic involvement can result in decreased vascular tone, sialorrhea, and increased gastrointestinal motility ${ }^{9}$. Stimulation studies have suggested lateralizing value for autonomic dysfunction: right insular stimulation increases sympathetic tone, whereas the stimulating the left insular region may favour parasympathetic activity $^{10}$.

Refractory status epilepticus (SE) refers to continuous or recurrent seizures that do not respond to first line therapies such as lorazepam, and two second-line standard anticonvulsant agents, such as phenytoin and valproate. The exact incidence of RSE is difficult to calculate since the definition is ambiguous, but may occur in up to $30 \%$ of cases ${ }^{11-14}$. Refractory SE represents a distinct group of patients with regard to treatment strategies, monitoring requirements, and outcomes, and with respect to some unique clinical syndromes and etiologies.

\section{Epidemiology and Prognosis of Status Epilepticus}

The first systematic summary of status epilepticus epidemiology was made by Hauser et $\mathrm{al}^{15}$, in Rochester MN based on retrospective data and antedating studies with continuous EEG (cEEG) monitoring. Their figure of $15 / 100,000 /$ year is almost certainly an underestimate given more recent findings. DeLorenzo et a $1^{16}$ conducted a prospective study in Richmond, VA that included cEEG monitoring and found an incidence of $41 / 100,000 /$ year. There is a marked difference among age groups, with a bimodal distribution of peak incidence in the elderly and children, with young adults being affected least commonly. Mortality was highest among the elderly, which may reflect more serious underlying etiology, or the effect of comorbidities. The most common cause of status epilepticus remains sub-therapeutic drug levels in patients with pre-existing epilepsy, followed by previous structural brain injury, stroke, hypoxic ischemic encephalopathy, metabolic causes (including uremia, electrolyte derangements, and hepatic failure), and drug or alcohol withdrawal ${ }^{17}$.

Mortality in SE has been well studied with several established risk factors identified, including duration of SE, age, and underlying etiology, with hypoxic-ischemic injury portending worse outcomes, and epilepsy or drug withdrawal showing more favourable outcomes ${ }^{18}$. Overall mortality is estimated at $14 \%$ for adults younger than 60 , but up to $38 \%$ for the elderly ${ }^{16}$. The impact of duration has been carefully studied by Drislane et $\mathrm{al}^{19}$, since earlier studies had dichotomized the

Table 2: Classification of status Epilepticus

Generalized Status Epilepticus
1. Tonic-clonic
2. Tonic (e.g., in Lennox-Gastaut)
3. Clonic (infants and children)
4. Myoclonic status (bilaterally symmetrical jerks, mainly with acute/ subacute brain disorders, including post-anoxic/ischemic injury)
5. Absence
6. Nonconvulsive generalized status (NCSE)

Partial Status Epilepticus

1. Simple partial (including epilepsia partialis continua)

2. Complex partial status epilepticus

3. NCSE with localization-related seizures, including transitional forms 
duration of SE as either shorter or longer than one hour, with mortality rates of $2.7 \%$ and $32 \%$ respectively ${ }^{15}$. These authors demonstrated that although shorter duration of SE was indeed correlated with less mortality (31\% for less than ten hours vs. $69 \%$ for longer), this difference was not significant once other known predictors were considered, such that even prolonged, refractory SE should not be considered a hopeless situation. These findings suggest that decisions about whether to withdraw care should probably be based on the prognosis for underlying cause and other comorbidities, as opposed to the duration of seizure activity. Focal seizures appeared to have a better prognosis in this study, although the impact of comatose patients after cardiac arrest seems to have skewed several categories of results, and a similar study excluding this population is warranted. A recent review by Neligan et $\mathrm{al}^{20}$ concluded that age and depth of coma were the only factors that consistently predicted outcome with any accuracy. Periodic epileptiform discharges (PEDs) are often suggestive of poor outcome, but these authors correctly assert that this likely represents the underlying etiology, which is commonly a destructive lesion in lateralized PEDs (PLEDs), or hypoxic-ischemic in origin for generalized PEDs (GPEDs).

\section{Pathophysiology of Status Epilepticus and Refractory Status Epilepticus}

The transition from single seizures to status epilepticus is mainly a result of progressive loss of the inhibitory surround through a number of mechanisms, in a time-dependent fashion ${ }^{21}$. The earliest changes during status epilepticus likely relate to neurotransmitter release and ion channel modulation, whereas later changes relate more to receptor trafficking. Finally, after days-weeks of repeated seizures, even the balance of neuropeptides favors excitation, and eventually gene expression is also altered ${ }^{22,23}$.

Early in the course of SE, gamma amino butyric acid-A $\left(\mathrm{GABA}_{\mathrm{A}}\right)$ receptors are endocytosed into clathrin-coated pits, and then transported either to the soma for degradation or back to the post-synaptic neuronal membranes after modification at the Golgi apparatus ${ }^{24}$. Over time, this leads to an overall downregulation of $\mathrm{GABA}_{\mathrm{A}}$ receptors. This likely explains the loss of efficacy of antiepileptic drugs (AEDs) whose mechanism of action is mainly related to potentiating the effects of $\mathrm{GABA}_{\mathrm{A}}$ mediated chloride conductance and membrane hyperpolarization. The efficacy of benzodiazepines drops 20-fold during the first 30 minutes of continuous seizures, whereas phenytoin loses its effect more slowly ${ }^{25}$. The mechanism triggering endocytosis of $\mathrm{GABA}_{\mathrm{A}}$ receptors is poorly understood, but may relate to repeated and prolonged exposure to ligands acting on $\mathrm{GABA}_{\mathrm{A}}$ receptors during $\mathrm{SE}$.

Further enhancing the excitation-inhibition imbalance, there is an augmentation of excitatory (and excitotoxic) activity with an increase in N-methyl-D-aspartate (NMDA) receptor availability $^{21}$. With increased calcium influx secondary to NMDA activation, there is activation of intracellular cascades culminating in caspase activation and apopototic ${ }^{26}$ and/or necrotic ${ }^{27}$ cell death. Caspase inhibitors have been explored and have shown some success in animal models ${ }^{28}$, but human data are lacking. In addition, the hippocampal damage can lead to a more persistent epileptic condition, if one was not present beforehand ${ }^{21}$, although definitive evidence for this process is wanting in humans. N-methyl-D-aspartate toxicity is supported by the effects of domoic acid and its association with causing seizures and brain injury ${ }^{29}$.

Based on this knowledge, a goal-directed approach to management can be defined, with the ultimate aim being prevention of secondary neuronal injury as a result of excitotoxicity during prolonged and unregulated NMDA activation. The above points also provide a framework for a rational pharmacotherapeutic approach to preventing brain injury as a result of status epilepticus, as outlined below.

\section{Management of Status Epilepticus}

The goals of management in status epilepticus are: 1) ensuring adequate vital functions (oxygenation and perfusion); 2) stopping the seizures; 3 ) preventing recurrent seizures; and 4) predicting and preventing systemic complications. A careful search for the underlying cause should always be pursued if this is not apparent at the outset. An overview of treatment options and corresponding clinical and physiologic changes is shown in Figure 1.

1. Stabilization: The presentation of convulsive status epilepticus is perhaps the most dramatic among emergency room patients, such that the initial focus is often on stopping the convulsions. While this is important, the usual priorities of resuscitation should remain the same, namely to ensure that the patient is oxygenated and maintaining an adequate blood pressure. The airway itself is often compromised due to sustained tonic or clonic contraction of the muscles of mastication such that placement of an endotracheal tube is not immediately possible; however, supplemental oxygen should be applied by mask, and if urgent intubation is required for severe hypoxia or systemic instability, a short-term paralytic may be employed, with the caveat that cEEG monitoring should be applied as soon as possible as paralytics will have no effect on the underlying cerebral epileptic activity despite apparent clinical improvement. Large bore IV access should be acquired, and bloodwork sent as clinically indicated, including glucose, electrolytes (including calcium, magnesium and phosphate), drug levels, toxicology, and arterial blood gas analysis. In general, it is not necessary to treat the patient with bicarbonate, even though a profound, combined metabolic (lactate) and respiratory (hypoventilation) acidosis is present. These blood gas abnormalities quickly resolve with correction of the seizures. If the patient shows a continuing anion-gap acidosis, this should raise suspicion of poisoning with a toxic agent such as ethylene glycol or methanol.

2. Stopping the seizures: At least two randomized controlled studies have demonstrated the effectiveness of lorazepam for treating status epilepticus. The San Francisco ambulance study showed that lorazepam (2 mg) IV was superior to diazepam or placebo in stopping seizures, although the difference between lorazepam and diazepam was small $^{30}$. An in-hospital study revealed that lorazepam was more effective than phenytoin in stopping acute seizures ${ }^{17}$, with minimal differences among the other drugs studied, including diazepam and phenobarbital. In most centers, a second-line agent such as phenytoin (PHT) is being administered simultaneously with abortive agents such as lorazepam. Due to the paucity of strong evidence favouring one 


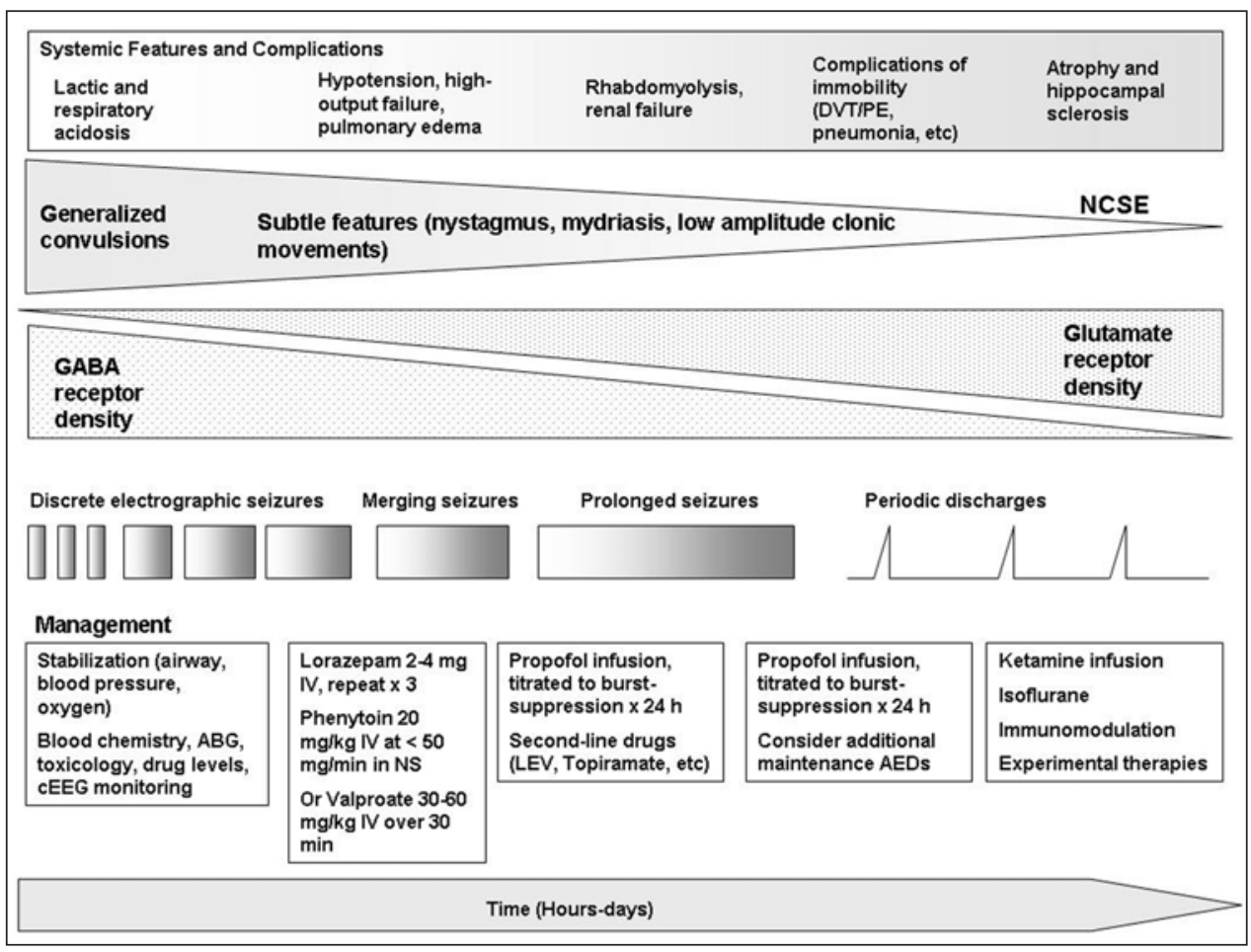

Figure 1: Clinical and physiologic changes over time in Status Epilepticus. DVT: Deep vein thrombosis; PE: Pulmonary embolus; NCSE: Nonconvulsive status epilepticus; GABA: Gamma-aminobutyric acid; ABG: Arterial blood gas; cEEG: Continuous electroencephalography; NS: Normal saline; LEV: Levetiracetam; AED: Antiepileptic drugs; IV: intravenous.

treatment protocol over another for early treatment of SE, wide variability exists in the strategies used between different centers $^{31}$. Recent evidence suggests that valproate may also be a reasonable first-line agent for treating SE. A pilot study of 68 patients $^{32}$ showed that valproate $(35 \mathrm{mg} / \mathrm{kg}$ IV) successfully terminated seizures in $66 \%$ of patients, compared to a $42 \%$ success rate for phenytoin ( $18 \mathrm{mg} / \mathrm{kg} \mathrm{IV})$. As a second line agent, valproate stopped seizures in $79 \%$ of cases whereas phenytoin showed an efficacy of only $25 \%$. A second comparative study ${ }^{33}$ found that valproate and phenytoin had similar efficacy at $88 \%$, although these authors included patients with 'acute repetitive seizures' in addition to those with true SE, partially explaining the high success rates with both drugs. Notably, $12 \%$ of patients treated with phenytoin experienced side effects, whereas none of those treated with valproate had adverse reactions. These results will need to be confirmed in larger studies, but do suggest that valproate may be suitable as a first-line therapy, especially for select populations who may not tolerate phenytoin. Finally, adequate doses must be used and based on body weight, rather than standard doses regardless of patient factors. One gram of phenytoin is often given as a standard dose, regardless of patient weight, which is often not enough to achieve therapeutic levels.

If seizures are ongoing after adequate repeated doses of lorazepam (i.e., $2 \mathrm{mg}$ repeated every two to three minutes for four doses) and initiation of a standard maintenance drug such as phenytoin or valproate, most conventional protocols suggest progressing to more sedating agents, such as phenobarbital. However, this necessitates definitive airway management and transfer to an ICU. In addition, phenobarbital often causes hypotension and vasopressor agents may be required.

Alternatively, and more commonly encountered in recent years, an intravenous anaesthetic such as propofol is used in this setting. Propofol also works via $\mathrm{GABA}_{\mathrm{A}}$ receptors, requires intubation and transfer to an ICU, and frequently lowers blood pressure. However, the advantage of propofol is its short half life, such that it can be weaned and restarted in a controlled fashion. Recently, a small randomized trial demonstrated longer mechanical ventilation for barbiturates compared to propofol, although the study was significantly underpowered ${ }^{34}$. Both groups demonstrated significant treatment related side-effects, and similar efficacy for terminating seizures. A single dose of propofol may rarely serve to abate the seizures and circumvent the need for transfer to ICU, but in general, use of this medication will require definitive airway management with intubation. If clinical seizures have stopped at this point and the EEG does not demonstrate ongoing ictal activity, it may suffice to monitor the patient closely and continue maintenance anticonvulsants. If either of these criteria are not met, anaesthetic drugs should be employed to achieve a burst-suppression pattern with cEEG monitoring. The optimal duration of burstsuppression, and the degree of EEG suppression (burstsuppression ratio), remain poorly defined due to a lack of trials 
comparing different protocols. Guidelines have been published $^{35,36}$, but are often non-specific when it comes to precise targets of treatment and are based mainly on expert opinion. By convention, the anaesthetic drug of choice is titrated to achieve burst-suppression for 24-48 hours, and then slowly weaned off with careful clinical and cEEG observation, repeating the cycle if necessary until successful weaning is achieved using therapeutic levels of maintenance antiepileptic drugs.

Prolonged stays in the ICU with anaesthetic agents titrated to burst-suppression are occasionally required (in rare cases up to several months), and do not necessarily indicate irreversible brain damage $\mathrm{e}^{37}$. Prolonged, high dose propofol infusion in such cases has been associated with the life-threatening propofol infusion syndrome (PRIS), characterized by hypotension, acidosis, renal dysfunction, and cardiac toxicity ${ }^{38}$. Occasionally, PRIS can manifest as sudden cardiovascular collapse in previously healthy patients who have been subjected to high doses of propofol ${ }^{39}$. The precise incidence of PRIS remains unknown, but in one prospective study of patients treated with propofol for more than 24 hours $^{40}$, 11 of 1017 patients $(1 \%)$ developed PRIS (defined in this study as metabolic acidosis and cardiac dysfunction, plus one of rhabdomyolysis, hypertriglyceridemia, or renal failure). Mortality was $18 \%$, and most patients showed signs of PRIS within the first 24 hours in retrospective analysis. Of concern is that only $18 \%$ of patients were receiving infusions greater than $5 \mathrm{mg} / \mathrm{kg} / \mathrm{hr}$, suggesting that even lower doses can predispose to PRIS. Laboratory monitoring and definitive management with adequate blood levels of a standard antiepileptic medication, such that propofol can be discontinued, are the mainstays of prevention. One report described successful resuscitation after cardiocirculatory arrest from PRIS using extracorporeal membrane oxygenation $(\mathrm{ECMO})^{41}$.

3. Preventing recurrence of seizures in the short term: The anti-epileptic effect of lorazepam is brief (probably 45 minutes maximum). To prevent recurrence of seizures, drugs with longer duration of action are used after lorazepam has provided early control. Most centres use phenytoin (PHT) given in normal saline (PHT precipitates in glucose solutions) at a rate no greater than $50 \mathrm{mg} / \mathrm{minute}$ to avoid hypotension, thought to be due to the propylene glycol diluent. However, fosphenytoin has also been reported to cause hypotension, suggesting a possible direct vasodepressor effect ${ }^{42}$. A loading dose of $15-20 \mathrm{mg} / \mathrm{kg}$ of PHT usually provides a serum concentration that is in the generally accepted therapeutic range of 40-80 micromol/L for 24 hours. While fosphenytoin is favoured in some centers due to its faster tolerable infusion rate, this prodrug must then be converted to PHT, such that the therapeutic effect may not actually be any faster than that of $\mathrm{PHT}^{43}$. There is no good evidence that fosphenytoin is more effective or safer than regular PHT, although it may be a good option when IV access is tenuous. A third option gaining favour is valproate, which can be given IV, and is probably equally effective and less prone to cause cardiovascular side effects. A loading dose of $30-60 \mathrm{mg} / \mathrm{kg}$ is well tolerated and side effects are rare, although patients with liver disease may have impaired metabolic clearance of valproate. Idiosyncratic effects include carnitine deficiency and hyperammonemia, a syndrome which may respond to replacement of carnitine intravenously ${ }^{44}$. Thus, if the level of consciousness remains impaired in patients who have been loaded with valproate with EEG improvement, it is reasonable to check the ammonia level. Similarly, new signs of parkinsonism should prompt consideration of carnitine deficiency when the onset correlates with valproate administration.

Levetiracetam (LEV) is used relatively commonly in some centers due to its favourable side effect profile and lack of interaction with other drugs. There is some evidence that LEV may have neuroprotective effects as well ${ }^{45}$. No loading dose is required, and it can be given intravenously at a dose of 500 to $1500 \mathrm{mg}$ twice per day. Due to its unique mechanism of action at the synaptic vesicle $2 \mathrm{~A}$ binding site, LEV can also be useful as adjunctive therapy by inhibiting pathologic neuronal activity in ways not addressed by other anticonvulsants. Unfortunately, an intravenous formulation is not currently available in Canada, such that effective serum levels are dependent upon the functional integrity of the gastrointestinal tract, which has often been influenced by other drugs used to treat seizures (including propofol, barbiturates, inhalational anaesthetics, and midazolam). Eue et $\mathrm{al}^{46}$ reported on their two year experience with intravenous LEV in SE, and found that after failure of benzodiazepenes, 19 of 43 patients responded to $1000-2000 \mathrm{mg}$ of LEV. No significant adverse reactions were reported. Berning et $\mathrm{al}^{47}$ retrospectively reviewed the charts of 32 patients treated with IV LEV (median Day 1 dose, $3500 \mathrm{mg}$ ) and reported a success rate of $72 \%$, including acute and remote etiologies. Topiramate has also been used with some success in generalized and complex partial SE, in doses of 300-1600 mg/day ${ }^{48}$. Since most side effects of topiramate are cognitive in nature, titration can be achieved quickly in the ICU setting, bearing in mind the risks for acidosis and nephrolithiasis.

4. Prevention and Treatment of Systemic Complications: The systemic complications of SE can be divided into immediate and delayed categories (Figure 1). The immediate risks relate to the systemic complications of the seizures themselves and include hyperthermia, lactic acidosis, pulmonary edema and hypoxia, rhabdomyolosis and renal failure, hyperglycemia, hyperkalemia, and sudden cardiovascular collapse ${ }^{49}$. Fever can certainly be due to the seizures themselves but should always raise the question of whether an infectious etiology is present. Hyperthermia may exacerbate systemic complications and brain injury, and there is some evidence that induced hypothermia can mitigate these effects $^{50,51}$. As with the acidosis that accompanies status epilepticus, most of the other immediate systemic effects are managed effectively by addressing the underlying cause and stopping the seizures. Awareness of these potential complications allows for appropriate monitoring and specific therapy when indicated.

Many patients presenting with SE will undergo diagnostic lumbar puncture to rule out infectious causes, and interpretation of the cerebrospinal fluid (CSF) parameters can be challenging, mainly with respect to the commonly encountered mildmoderate leukocytosis. Barry and Hauser ${ }^{52}$ studied the CSF parameters of 217 consecutive patients with SE of any cause, and found that among those with conditions usually associated with normal CSF (ie: not infectious or traumatic), the highest cell count was $28 \times 10^{6} / \mathrm{L}$. Another study of 102 patients with seizures found that up to $30 \%$ may have pleocytosis without 
other explanation ${ }^{53}$, with a range of 3 to $464 \times 10^{6} / \mathrm{L}$ and a mean of $72 \times 10^{6} /$ L. Ultimately, one can only conclude that seizures alone can cause a modest pleocytosis, but also that this should be a diagnosis of exclusion if there are any features to suggest a possible infectious etiology.

\section{Refractory Status Epilepticus}

If two standard drugs such as phenytoin and valproate fail after lorazepam, the patient is considered to have refractory status epilepticus ${ }^{11}$. All patients in this category should be intubated and transferred to an ICU for more aggressive management. Propofol and midazolam are commonly recommended at this stage ${ }^{54}$. As mentioned, propofol acts directly on $\mathrm{GABA}_{\mathrm{A}}$ receptors, with some modulation of calcium channels and inhibition of NMDA receptors, while midazolam acts mainly on the benzodiazepine site of $\mathrm{GABA}_{\mathrm{A}}$ receptors. Midazolam has a higher failure rate than propofol ${ }^{55}$ and propofol is generally preferred, although care must be taken to avoid high dose, prolonged infusions for reasons mentioned above. High dose anaesthetic barbiturates (thiopental or pentobarbital) are effective and are still used; however, with prolonged use their half-life is protracted and they can interfere with ciliary action, predisposing already susceptible patients to ventilator acquired pneumonia $(\mathrm{VAP})^{56}$.

\section{Ketamine}

Ketamine has the theoretical advantage of being an NMDA antagonist with reasonable experimental evidence for treatment of refractory $\mathrm{SE}^{57,58}$, whereas human data is mainly limited to case reports ${ }^{59}$. Ketamine has also been suggested as a neuroprotective agent ${ }^{60}$. One small retrospective study showed good control with ketamine in five of seven patients with refractory status epilepticus ${ }^{61}$. Interestingly, ketamine does not seem to be as effective as conventional GABA agonist drugs early in the course of illness, but can provide 'rescue' therapy when these agents fail. This would appear consistent with the time-dependent down-regulation of GABA receptors and upregulation of NMDA receptors in status epilepticus. After metabolism to nor-ketamine, it binds weakly to the phencyclidine site within the NMDA channel, which can lead to symptoms of psychosis during emergence in some patients ${ }^{48}$. Ketamine may offer hemodynamic advantages in that it generally does not cause hypotension, and may in fact support blood pressure due to catecholamine release ${ }^{62}$, which can also lead to tachycardia. Potential adverse effects include raising intracranial pressure ${ }^{63}$, although clinically significant changes in intra-cranial pressure (ICP) are not reported in the literature. The doses used are variable, but a reasonable starting point is $1-1.5$ $\mathrm{mg} / \mathrm{kg}$ loading dose followed by an infusion at $0.5 \mathrm{mg} / \mathrm{min}$, titrating as necessary to achieve burst-suppression on the electroencephalogram and maintaining this for at least 24 hours. There is some evidence for a synergistic effect of ketamine when administered with benzodiazepines ${ }^{64}$. The therapeutic window for ketamine is wide, with very few side effects reported even at high doses. One case report raised concerns after a 44 year-old male with known neurosyphilis and SE was treated with ketamine at doses up to $7.5 \mathrm{mg} / \mathrm{kg} / \mathrm{hour}$ for several days, which terminated the seizures ${ }^{65}$. The patient was left with cognitive deficits and cerebral atrophy, which may be consistent with toxicity related to NMDA-blockade, although this has not been reported in previously well individuals, and is difficult to distinguish from the consequences of SE itself, or from longstanding neurosyphilis. Animal models have demonstrated potential developmental toxicity related to ketamine ${ }^{66}$. Our own experience with ketamine, while limited to a few cases, has been mixed - seizures are often suppressed temporarily, but seem to recur quickly after stopping the infusion. Furthermore, burstsuppression has been difficult to achieve unless combined with a second agent, such as midazolam.

\section{Inhalational Anaesthesia}

Inhalational anaesthetics provide another option for refractory status epilepticus, although these agents have significant practical limitations. Isoflurane and desflurane work within minutes, are easily titratable, and are remarkably effective in stopping status epilepticus ${ }^{67,68}$. The safety of isoflurane has now been demonstrated (in a case report) with duration of use up to 26 days, although most patients will require vasopressor support and infection rates are probably increased ${ }^{68}$. The mechanism of inhalational agents is not well understood, but they likely have some GABA agonist properties, and may influence thalamocortical connections as well ${ }^{69-71}$. Using these agents requires an anaesthetist and vapour extraction system in the ICU. Like other agents at higher concentrations, and with prolonged use, these drugs can cause hypotension, paralytic ileus, and prolonged sedation as they redistribute from fat stores. In cases where suppression of epileptiform discharges is proving challenging, or propofol infusion syndrome is encountered, isoflurane is highly effective for suppression of the EEG and achieving a more aggressive "suppression-burst" pattern.

\section{Hypothermia}

Hypothermia has gained favour as a neuroprotective strategy in recent years, largely as a result of its clear efficacy in improving outcomes after cardiac arrest ${ }^{72,73}$. More recently, based on experimental evidence for an anticonvulsant effect of hypothermia ${ }^{74-76}$, Corry et $\mathrm{al}^{77}$ treated four patients with refractory status epilepticus with therapeutic hypothermia, with successful resolution of status in all four cases, but with reported adverse effects including mild coagulopathy and one case of sepsis. Given the growing experience with therapeutic hypothermia in most centers, this seems a relatively safe option for refractory patients who have failed multiple medical treatments. Complications are rare when moderate hypothermia (32-34 degrees Celsius) is administered for less than 48 hours $^{72,73}$, and a neuroprotective effect is probable, even if seizures are not completely abolished.

\section{Surgical Options}

Epilepsy surgery has occasionally been employed in desperate situations to stop refractory seizures of focal origin ${ }^{78-}$ ${ }^{80}$. Case reports and small series have described variable success with multiple subpial transections ${ }^{81-83}$, focal resections ${ }^{84}$, hemispherectomy ${ }^{85}$ and vagal nerve stimulation ${ }^{86,87}$. Surgery may be life-saving in some circumstances, and should be considered as an option for patients with status epilepticus originating from a focal lesion (or a non-lesional but well- 
defined focus) after carefully weighing the expected deficits that could result from surgery and exhausting medical treatment options.

\section{Electroconvulsive Therapy (ECT)}

Electroconvulsive therapy has been discussed as a rescue therapy for refractory status epilepticus in several case reports with variable success ${ }^{88-91}$. Kamel et $\mathrm{al}^{92}$ reported success in two of three patients treated with several days of electroconvulsive therapy after failure of multiple medications. Previous work has suggested that ECT may upregulate endogenous inhibitory mechanisms ${ }^{93}$, although this has been demonstrated only in animals and in human patients without seizure disorders. Whether this rather counter-intuitive method applies to the physiology of human status epilepticus remains to be seen, and larger trials may be warranted.

\section{Nonconvulsive Seizures and the Role of Continuous EEG (cEEG) Monitoring}

In general ICUs, up to $19 \%$ of comatose patients will experience seizures, of which $90 \%$ will be nonconvulsive ${ }^{94}$. Among patients who remain comatose after convulsive seizures, the prevalence of NCS is roughly $48 \%{ }^{95}$ and at least $20 \%$ among patients with acute structural brain lesions, including trauma. Comatose patients require at least 48 hours of continuous EEG (cEEG) recording to detect more than $90 \%$ of seizures; standard (20-30 minute) recordings are inadequate, detecting fewer than $10 \%$ of seizures found with prolonged recordings ${ }^{95}$. It is generally acknowledged that convulsive status epilepticus leads to neuronal injury, and that absence status epilepticus does not contribute to morphological or functional changes, but the impact of other types of NCSE remains unproven ${ }^{96}$. Although there is abundant support that neuronal death, especially in the hippocampus, does occur in animal models of NCSE ${ }^{97-101}$, it has been difficult to establish this in human cases. Evaluating the relative contributions of the underlying etiology, convulsive seizures, and non-convulsive seizures in causing brain damage has always been problematic. The conditions causing NCSE in the ICU are the same as those causing convulsive seizures, including trauma, anoxic-ischemic encephalopathy, encephalitis, vascular lesions, neoplasms, metabolic disorders, sepsis and preexisting epileptic conditions. Many of these are independently associated with significant cerebral injury. How can we dissociate injury due to these processes from damage attributable to the seizures themselves? This question has enormous potential clinical importance, since NCSE is common in ICU (especially neuro-ICU) patients, and may be one of very few conditions amenable to treatment that affects outcome for brain injured patients.

The ICU is riddled with barriers to EEG recording, including a multitude of unusual artifacts, although most of these can be addressed by an experienced technologist and electroencephalographers ${ }^{102}$. In addition, EEG technologists are often not available outside of usual work hours. Several approaches have been developed out of necessity to make some form of EEG monitoring available that can be set up by nurses and residents, displayed continuously at the bedside, and saved for later analysis.
The Bispectral Index (BIS) ${ }^{103}$, which was originally developed to study ocean wave motion ${ }^{104}$ and seismic activity ${ }^{105}$, has been proposed as a useful measure of patient sedation, providing a number between 0 (deep sedation) and 100 (normal wakefulness). The index is calculated from a proprietary computer algorithm that incorporates EEG data, and also includes an electromyelogram (EMG) monitor and a signal quality monitor. Since the EEG morphology cannot be assessed using BIS, monitoring for seizures is obviously limited. One report compared the BIS value with conventional EEG in a patient with SE and found that the BIS increased during seizures, and decreased when the seizures were controlled ${ }^{106}$. The patient was unresponsive throughout, even with high BIS values, which they interpreted to mean that seizures were causing the elevated BIS values, and therefore that BIS may be useful when EEG is not available. A second report used BIS to monitor a patient with encephalitis and frequent seizures ${ }^{107}$, and again found that the BIS values increased during seizure activity, correlating with EEG findings. In both cases, seizures were treated with anaesthetic agents, which would clearly affect the BIS values with or without seizures. In addition, there are multiple potential sources of artefact in the ICU, which would be impossible to exclude as contributors to the BIS value without seeing the waveform morphology. While this may be a case of "better than nothing" brain monitoring, the potential for false positives and aberrant administration of anaesthetic medications makes using BIS to monitor seizures a risky endeavour.

A subhairline EEG system was originally described by Bridgers and Ebersole ${ }^{108}$ Young et al ${ }^{109}$ later studied the efficiency of a subhairline EEG system with sticker electrodes in comatose ICU patients, and found a sensitivity of $70 \%$, and specificity of greater than $90 \%$ for seizure detection as compared to simultaneous conventional EEG recordings. This sensitivity may have been limited by a relatively low sampling rate which has since been improved, but likely also reflects suboptimal spatial coverage. Nonetheless, detecting $70 \%$ of seizures (almost all of which were nonconvulsive) seems intuitively better than detecting $0 \%$, while awaiting more formal EEG monitoring. Other temporary systems designed to provide a quick view until more complete monitoring is available have been described, including a proposed seven electrode system ${ }^{110}$ that could be placed by nurses or residents using surface landmarks as opposed to measurements. Using conventional EEG reformatted to this simplified montage, these authors found a sensitivity and specificity of greater than $90 \%$; however, whether this would apply in a real-world ICU application remains to be seen. A variety of caps, nets, and other placement systems are also available, although with substantial cost, and still requiring a separate EEG machine to be available at the bedside.

An ideal quick-access EEG monitoring system will include good coverage of the head, be easily placed after minimal training, displayed on the bedside monitor and recorded for later review, and meet most of the technical standards outlined by the Canadian Society for Clinical Neurophysiology $y^{111}$. Structured training should be available at a basic level such that bedside nurses, intensivists, and residents can initiate recording and interpret basic patterns. Such training would likely require participation from a neurologist/neurointensivist certified in EEG and familiar with the system, and a technician from the 
manufacturing company. However, even a system meeting this description would still be regarded as a temporary tool until formal EEG assessment is available; continuous EEG with a full array of electrodes applied using the 10-20 configuration should still be considered the gold standard, if not standard of care.

The diagnosis of NCSE is problematic for several reasons, not the least of which is the lack of a gold standard by which to define the sensitivity of various criteria, perhaps with the exception of intracranial depth electrodes, although even this invasive technique has limitations in spatial coverage. It is commonplace for the same scalp EEG pattern to be interpreted differently between electroencephalographers, emphasizing the importance of considering these patterns as part of an ictalinterictal continuum. Criteria for NCSE have been developed ${ }^{87}$ but can be cumbersome for those inexperienced in EEG (Table 3). Furthermore, the usual evolutionary pattern that defines isolated seizures may not always be appreciated in selfsustaining status epilepticus, where a more monotonous sequence of discharges, without evolutionary changes, may represent ongoing ictal activity. Again, this leaves room for subjectivity when deciding whether sequential spikes or sharp waves represent periodic interictal epileptiform discharges or ongoing seizures. In these circumstances, treatment decisions are based on input from an experienced electroencephalographer who is able to consider the possibilities in the appropriate clinical and electrophysiological context, until clear criteria can consistently distinguish between the two entities. Ideally, the neurologist or neuro-intensivist involved in the patient's care is also responsible for reviewing the EEG recordings to allow for accurate clinical correlation, and for careful weighing of pros and cons of seizure management based on comorbidities and concurrent medications. When this is not the case, video EEG is invaluable in helping the electroencephalographer correlate EEG findings with clinical information, including potential generators of artifacts, and subtle correlates of epileptiform activity.

Another common difficulty is distinguishing between triphasic waves (TWs), which usually indicate a metabolic

Table 3: EEG criteria for NCSE (adapted from Young et $\mathrm{al}^{95}$ )

Primary Criteria

1. Repetitive generalized or focal epileptiform discharges at $>3 / \mathrm{sec}$

2 . Repetitive generalized or focal at $<3 /$ second and secondary criterion \#4

3. Sequential rhythmic waves and secondary criteria 1,2 and

3 with or without 4 .

Secondary criteria

1. Incrementing onset: increase in voltage and/or increase in frequency.

2. Decrementing offset: decrease in voltage or frequency.

3. Post-discharge slowing or voltage attenuation.

4. Significant improvement in clinical state or baseline EEG after

anti-epileptic drug encephalopathy, and generalized periodic epileptiform discharges (GPEDs), which can be an ictal phenomenon. Specifically, this problem arises when there are potential clinical correlates for both patterns, such as the post cardiac-arrest patient with organ dysfunction. A study of the morphology and reactivity of these two patterns offers some useful hints with high inter-rater reliability among blinded readers, but the sensitivity and specificity of several individual criteria remain relatively low, leaving significant freedom for subjective interpretation. In the best study of this distinction so far, Boulanger et $\mathrm{al}^{112}$ found that a sharp initial negative, faster repetition rate of the discharges, lack of an anterior-posterior time lag, lack of response to stimulation, and a faster background frequency all favoured nonconvulsive seizure activity over triphasic waves. While these clues are generally useful in making the distinction, the circular nature of the comparison in this study is problematic. For example, triphasic waves were considered 'correctly identified' by the blinded readers if they had met available criteria for TW's according to the authors interpretation. The nature and biologic generator of triphasic waves has yet to be determined, as has their precise position on the ictal-interictal continuum. In general, the clinical scenario combined with the above points is usually sufficient to decide whether a patient is in generalized NCSE or suffering from a metabolic encephalopathy, but uncertainty still commonly arises.

We have seen several cases of NCSE resulting in significant brain injury not attributable to other causes, mainly with respect to hippocampal injury with severe and persistent anterograde memory impairment leading to near total dependence (Figure 2). In most cases, NCSE is undetectable without cEEG monitoring, which also provides a guide for titration of AEDs or anaesthetic

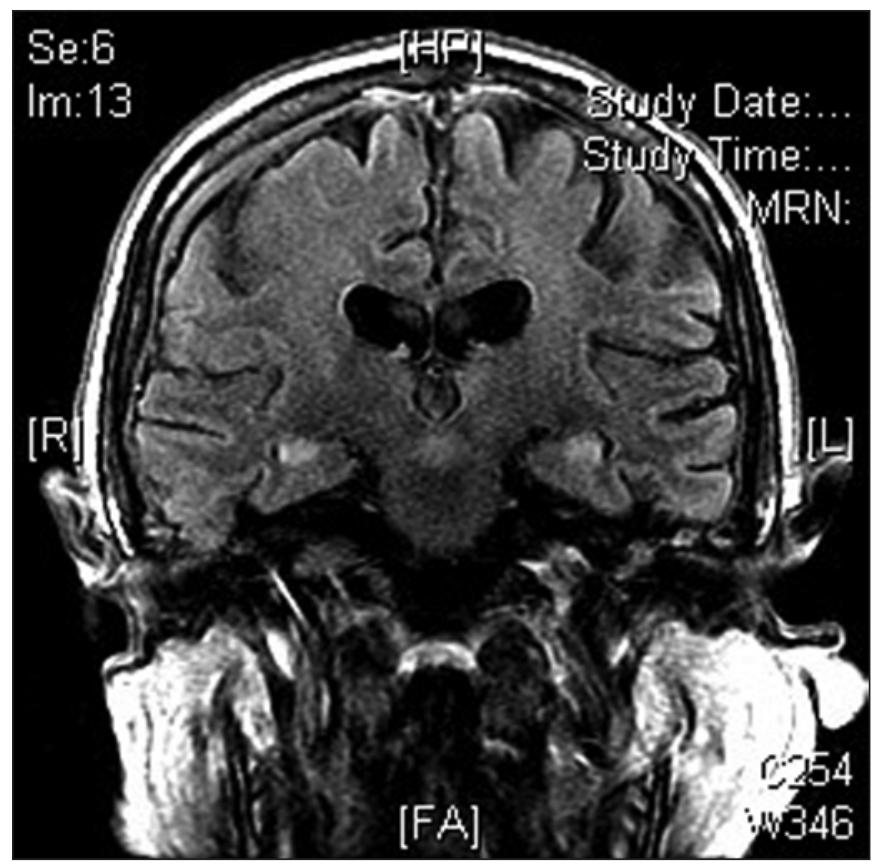

Figure 2: Bilateral increased FLAIR signal in mesial temporal structures after prolonged nonconvulsive seizures during a septic illness. 
agents to achieve a burst-suppression pattern. Whether detection and treatment of nonconvulsive seizures in the ICU improves outcomes has not been systematically addressed, but it is clear that NCS are a pathological response to brain dysfunction, and treatment seems warranted.

\section{Neuroimaging in Status Epilepticus}

Imaging of the brain with magnetic resonance (MR) during status epilepticus is usually pursued for diagnostic purposes, and may disclose a number of fairly specific clues as to the underlying etiology, especially related to structural lesions. In cases not related to structural lesions, the most commonly encountered changes are focal areas of increased T2/FLAIR signal secondary to encephalitis/cerebritis, and mesial temporal signal abnormalities in limbic encephalitis (either paraneoplastic [Anti-Hu, Anti-NMDA ${ }^{113}$ ], infectious Herpes simplex virus [HSV] or primarily autoimmune [Anti-VGKC $\left.{ }^{114}\right]$ ). In cases of unclear etiology, a multitude of other changes have been described and attributed to the seizures themselves, although the mechanism remains unclear.

Animal studies have shown that the diffusion-weighted MR (DWI) changes seen after prolonged seizures in lithiumpilocarpine models correlate well with areas of neuronal injury ${ }^{115,116}$. In humans, DWI changes involving a variety of anatomical regions have been described, including the pulvinar nucleus of the thalamus ${ }^{117,118}$, splenium of the corpus callosum, mesial temporal lobes, focal cortical areas in a gyral pattern, and as a crossed cerebellar diaschisis ${ }^{119}$. These areas of DWI abnormality are thought to represent a combination of cytotoxic and vasogenic edema as a result of metabolic failure. For superficial areas of restricted diffusion, the MR findings seem to correlate with electrographic localization ${ }^{120}$. In one report, MR changes were entirely restricted to the right hemisphere in a patient with callosal dysgenesis and NCSE originating from the right hemisphere ${ }^{121}$, again supporting a primary role for seizures causing the MR findings. Rarely, status epilepticus of focal origin can present with reversible tumour-like lesions involving thickened cortical areas and local enhancement with gadolinium, which later become atrophic and show local gliosis ${ }^{122}$. Using diffusion tensor imaging (DTI), there is now evidence that SE may also cause white matter injury, especially affecting the corpus callosum and fornices ${ }^{123}$.

Another finding of uncertain significance is leptomeningeal enhancement $^{119,124}$, which can complicate the diagnostic process, especially if there is also a CSF pleocytosis. Exclusion of infiltrative processes such as infection, granulomatous disease, and malignancy should be pursued before attributing these changes to seizures. Finally, diffuse atrophy with preferential involvement of mesial temporal structures (Figure 3) has been described $^{125}$, although some have argued that these changes may be at least partly reversible, particularly in cases of autoimmune encephalitis.

\section{Prognosis for Survivors}

While mortality and its predictors have been relatively well described, outcomes among survivors of SE have not been thoroughly studied. Since the expected functional outcome has major implications for treatment goals, this is a significant short-
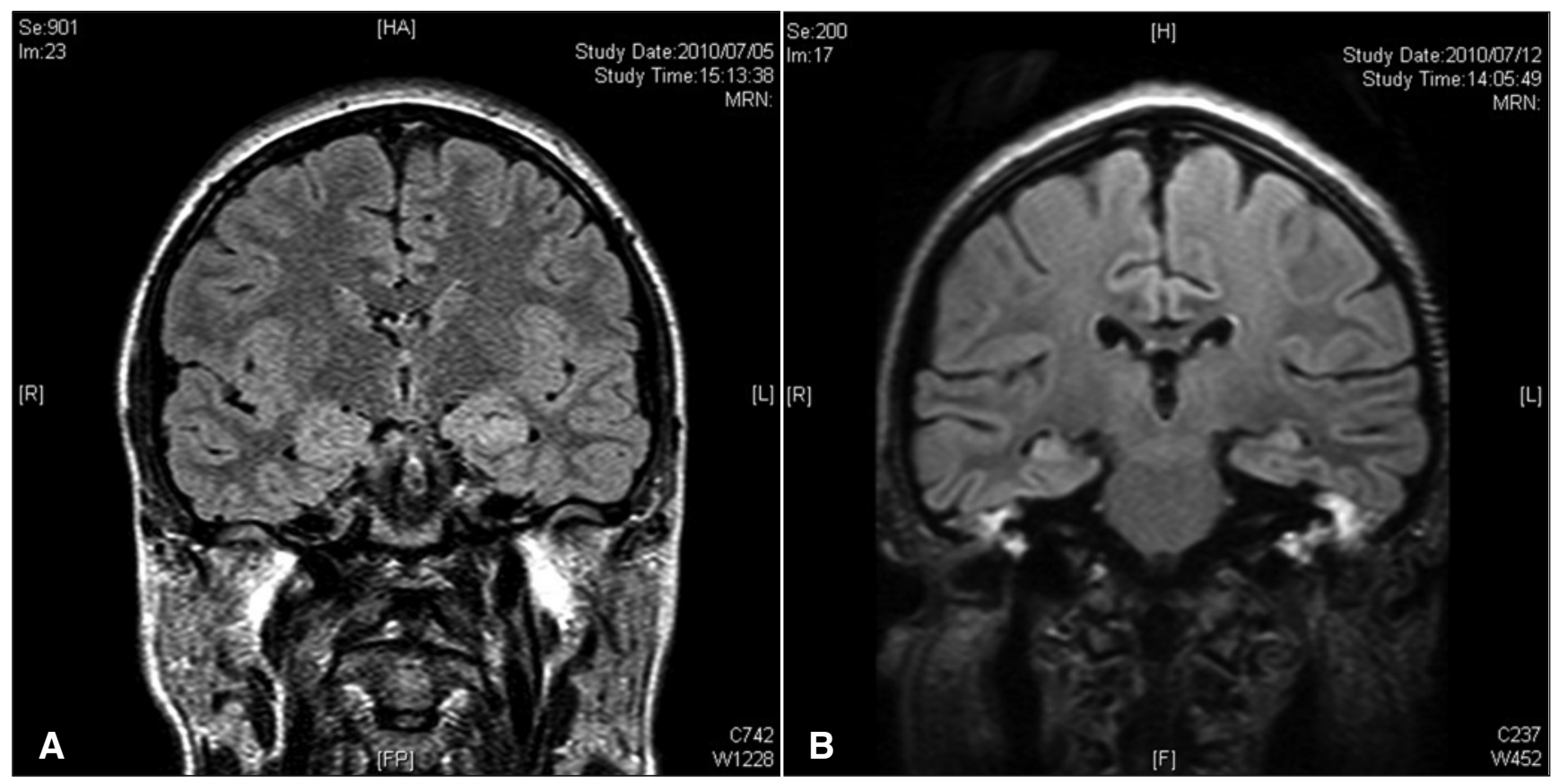

Figure 3: A) Coronal FLAIR MRI early in the course of refractory status epilepticus (New-onset refractory Status Epilepticus, or NORSE). Note the normal brain volume and increased signal in the hippocampi. B) Coronal MRI after prolonged status epilepticus in same patient as (3a), now showing diffuse atrophy and focal changes in both hippocampal regions. 
coming of the existing literature. Most of the available work describes outcomes in terms of overall functional capacity as it relates to composite functional scoring systems such as the modified Rankin scale ${ }^{126}$ or Glasgow outcome scale ${ }^{127}$, but provides little insight into the specific types of deficits patients and their families are left to deal with. More descriptive reports of the types of deficits the patients experience are limited to case reports ${ }^{128,129}$, which suggest that memory is often impaired irreversibly, as might be expected due to known hippocampal injury after prolonged seizures. This has certainly been our experience, and seems consistent with expert opinion among epileptologists and intensivists. There is some conflicting evidence, however, to suggest that status epilepticus itself may not have a direct impact on cognitive outcome, when comparing epileptic patients with SE versus those without ${ }^{130}$. These authors found that both groups declined in subsequent cognitive assessments, but that there was no difference between the two groups with respect to incidence. The mean duration of SE in this study was 12 hours. These findings may be more supportive of cognitive decline among epileptic patients in general as opposed to showing lack of effect of SE. Neligan et $\mathrm{al}^{20}$ reviewed the available literature and concluded that the evidence does not support the clinical impression that cognitive function is at risk in SE, but this conclusion may not accurately represent the data presented (which is largely retrospective). Further data from registries should provide more accurate estimates of the impact of SE on cognitive outcomes, and will likely support the consistent observation that SE does impact cognition, mainly in the memory domain. The reversibility of memory impairment after a single episode of status epilepticus is another unanswered question, and long term follow-up studies are required.

\section{New Onset Refractory Status Epilepticus: NORSE Syndrome}

Rarely, a young and previously healthy patient presents with seizures after a preceding viral prodrome, often with headache and fever, and then progresses into refractory status epilepticus ${ }^{131-133}$. One series of well-defined NORSE syndrome patients was described by Costello et al ${ }^{134}$. NORSE is a cryptogenic syndrome that likely encompasses infectious and non-infectious or autoimmune causes, often with equivocal or heterogeneous laboratory and imaging results and an unclear etiology. Historically these cases have been attributed to viral encephalitis, which is difficult to disprove, but as the spectrum of autoimmune encephalopathies becomes better elucidated, this pathophysiology seems a more likely candidate. Criteria have been suggested ${ }^{131,134}$, and are mainly based on exclusion of a comprehensive list of known causes of new-onset seizures. Patients are generally young (mean age 29 years), more often female, and initial imaging is usually normal but may later show patchy increased T2/FLAIR signal. Cerebrospinal fluid generally shows a mild lymphocytic pleocytosis with otherwise normal parameters. The EEG may demonstrate focal, multifocal, or generalized epileptiform activity, and seizures are refractory to usual first and second-line agents. Despite a suspicion of autoimmune mechanisms, immunomodulation with steroids, plasma exchange, and IVIG has been largely ineffective in managing this group of patients. This may represent the development of self-sustaining seizures via mechanisms previously discussed, even though the original insult has resolved. In one case of SE that fits the description of NORSE well, intrathecal synthesis of anti-GAD antibodies was discovered which prompted successful therapy with cyclophosphamide ${ }^{135}$. Pathology specimens from four patients showed non-specific microglial activation and gliosis ${ }^{131}$. Five of six patients survived, but only one had a good outcome, while the others were severely impaired and dependent, often with difficult epilepsy. Other unusual causes of status epilepticus to be considered include undetected mitochondrial disease, atypical infections such as from Bartonella henselae (cat-scratch disease), and genetic disorders ${ }^{136}$.

\section{Conclusions}

Status epilepticus is a medical emergency and should be treated with early aggressive therapy to ameliorate brain damage, systemic complications, and mortality. There is now substantial evidence that both convulsive and non-convulsive seizures are damaging to the brain and have the potential to become self-sustaining, even after the inciting cause has been addressed. Continuous EEG monitoring is strongly advised to rule out ongoing NCS, especially in obtunded patients in the ICU. Lorazepam followed by phenytoin or valproate is an appropriate initial treatment and other second line agents including topiramate and levetiracetam are gaining favour (drugs used for treatment of SE are summarized in Table 4). More consistent treatment protocols should be established using outcome data from large international registries to provide optimal evidence-based, goal-directed care. Outcome data among survivors of SE is lacking and further work in this area is needed to help guide difficult management decisions.

For refractory status epilepticus, ICU management is mandatory. Propofol is commonly employed and usually effective; ketamine and inhalational anaesthesia are useful alternatives with good safety profiles if propofol is fails, while surgical options and ECT remain unproven and carry significant morbidity. Hypothermia has some evidence and is also welltolerated, but with known risks, mainly related to infection. The role of NCSE in causing brain injury remains to be proven

Table 4: Anticonvulsant drugs in status epilepticus

\begin{tabular}{|c|c|c|c|}
\hline Drug & Dose & Infusion Rate & Precautions and interactions \\
\hline Lorazepam & $2 \mathrm{mg}$ IV, repeat x 3-4 doses & 1-2 min & $\begin{array}{l}\text { Sedation } \\
\text { Slow to clear in hepatic failure }\end{array}$ \\
\hline Phenytoin & $\begin{array}{l}15-18 \mathrm{mg} / \mathrm{kg} \text { IV load, mixed in } \\
\text { normal saline (precipitates in } \\
\text { glucose) }\end{array}$ & No faster than $50 \mathrm{mg} / \mathrm{min}$ & $\begin{array}{l}\text { Bradycardia, hypotension, skin } \\
\text { irritation, rash, nystagmus, elevated } \\
\text { liver enzymes } \\
\text { Slow to clear in hepatic failure } \\
\text { Drug interactions }\end{array}$ \\
\hline Fosphenytoin & $15-20 \mathrm{mg} / \mathrm{kg} \mathrm{IV}$ & $100-150 \mathrm{mg} / \mathrm{min}$ & $\begin{array}{l}\text { Similar side effects to Phenytoin with } \\
\text { less frequency } \\
\text { Must be metabolized to phenytoin; } \\
\text { onset of action similar despite faster } \\
\text { infusion rate }\end{array}$ \\
\hline Valproate & 30-60 mg IV & $\begin{array}{l}\begin{array}{l}\text { Over } 30 \mathrm{~min}-1 \text { hour, probably } \\
\text { safe at faster rates }\end{array} \\
\end{array}$ & $\begin{array}{l}\text { Caution with impaired hepatic function. } \\
\text { Rare hyperammonemic syndrome }\end{array}$ \\
\hline Levetiracetam & \begin{tabular}{|l}
$1500 \mathrm{mg}$ po or IV (not available \\
in Canada currently)
\end{tabular} & $\begin{array}{l}\begin{array}{l}\text { Undefined - rapid infusions } \\
\text { have not shown significant } \\
\text { adverse outcomes }\end{array} \\
\end{array}$ & \begin{tabular}{|l} 
Minimal \\
No significant drug interactions
\end{tabular} \\
\hline Propofol & $1 \mathrm{mg} / \mathrm{kg} \mathrm{IV}$ & $\begin{array}{l}1-2 \mathrm{mg} / \mathrm{kg} / \mathrm{hr} \text {, titrate to burst- } \\
\text { suppression on EEG }\end{array}$ & $\begin{array}{l}\text { Propofol infusion syndrome } \\
\text { Hypotension, sedation } \\
\text { Requires ICU }\end{array}$ \\
\hline Clobazam & 10-30 mg po bid & & \begin{tabular}{|l|} 
Sedation \\
\end{tabular} \\
\hline Topiramate & $300-1600 \mathrm{mg} / \mathrm{day}$ & & \begin{tabular}{|l} 
Mainly cognitive side effects, may \\
titrate quickly for SE \\
Acidosis, nephrolithiasis
\end{tabular} \\
\hline
\end{tabular}


definitively, but experience and basic science data suggest that NCSE should also be aggressively treated, such that vulnerable patients should be monitored for 48 hours with cEEG to detect and treat most cases of NCSE. The NORSE syndrome continues to be defined as a cryptogenic cause of refractory SE in previously healthy young individuals, and may be due to an as yet undefined autoimmune etiology.

\section{REFERENCES}

1. Gastaut H, Roger J, Lob H. Les états de mal épileptique: compte rendu de la reunion européene d'information électroencéphalographique. Xth Colloque de Marseille, 1962. Masson, Paris.

2. Meldrum BS, Vigouroux RA, Brierley JB. Systemic factors and epileptic brain damage. Prolonged seizures in paralyzed, artificially ventilated baboons. Arch Neurol. 1973 Aug;29(2): 82-7.

3. DeLorenzo RJ, Garnett LK, Towne AR, et al. Comparison of status epilepticus with prolonged seizure episodes lasting from 10 to 29 minutes. Epilepsia. 1999; 40: 164-9.

4. Theodore WH, Porter RJ, Albert P, et al. The secondarily generalized tonic-clonic seizure: a videotape analysis. Neurology. 1994; 44: 1403-7.

5. Treiman DM, Walton NY, Kendrick C. A progressive sequence of electroencephalographic changes during generalized convulsive status epilepticus. Epilepsy Res. 1990 Jan-Feb; 5(1): 49-60.

6. Kaplan PW. EEG monitoring in the intensive care unit. Am J Electroneurodiagnostic Technol. 2006 Jun; 46(2): 81-97.

7. Goodman JH, Homan RW, Crawford IL. Kindled seizures activate both branches of the autonomic nervous system. Epilepsy Res. 1999; 34: 169-76.

8. Freeman R, Schachter SC. Autonomic epilepsy. Sem Neurol. 1995; 15: $158-66$

9. Baumgartner C, Lurger S, Leutmezer F. Autonomic symptoms during epileptic seizures. Epileptic Disord. 2001; 3(3): 103-16.

10. Oppenheimer SM, Gelb A, Girvin JP, et al. Cardiovascular effects of human insular cortex stimulation. Neurology. 1992; 42: 1727-32.

11. Mayer SA, Claassen J, Lokin J, Mendelsohn F, Dennis LJ, Fitzsimmons BF. Refractory status epilepticus: frequency, risk factors, and impact on outcome. Arch Neurol. 2002; 59(2): 205-10.

12. Holtkamp M, Othman J, Buchheim K, Meierkord H. Predictors and prognosis of refractory status epilepticus treated in a neurological intensive care unit. J Neurol Neurosurg Psychiatry. 2005; 76(4): 534-9.

13. Rossetti AO, Logroscino G, Bromfield EB. Refractory status epilepticus: effect of treatment aggressiveness on prognosis. Arch Neurol. 2005; 62(11): 1698-702.

14. Novy J, Logroscino G, Rossetti AO. Refractory status epilepticus: a prospective observational study. Arch Neurol. 2005 Nov; 62 (11): 1698-702.

15. Hauser WA. Status epilepticus: epidemiology considerations. Neurology. 1990; 40 Suppl 2: 9-12.

16. DeLorenzo RJ, Towne AR, Ko D, et al. Prospective, populationbased epidemiological study of status epilepticus in Richmond VA. Neurology. 1996; 46: 1029-32.

17. Treiman DM, Meyers PD, Walton NY, et al. A comparison of four treatments for generalized convulsive status epilepticus. N Eng J Med. 1998; 339: 792-8.

18. Towne AR, Pellock JM, Ko D, et al. Determinants of mortality in status epilepticus. Epilepsia. 1994;5:27-36.

19. Drislane FW, Blum AS, Lopez MR, Gautam S, Schomer DL. Duration of refractory status epilepticus and outcome: loss of prognostic utility after several hours. Epilepsia. 2009 Jun; 50(6): 1566-71.

20. Neligan A, Shorvon SD. Prognostic factors, morbidity and mortality in tonic-clonic status epilepticus: a review. Epilepsy Res. 2011; 93(1): 1-10.
21. Wasterlain CG, Liu H, Naylor DE, et al. Molecular basis of selfsustaining seizures and pharmacoresistance during status epilepticus: the receptor trafficking hypothesis revisited. Epilepsia 2009; 50 Suppl 12: 16-18.

22. Sperk G, Wieser R, Widmann R, Singer EA. Kainic acid induced seizures: changes in somatostatin, substance $\mathrm{P}$ and neurotensin. Neuroscience. 1986; 17: 1117-26.

23. Wasterlain CG. Inhibition of cerebral protein synthesis by epileptic seizures without motor manifestations. Neurology. 1974; 24 : 175-80.

24. Kapur J, Macdonald RL. Rapid seizure-induced reduction of benzodiazepine and $\mathrm{Zn}^{2+}$ sensitivity of hippocampal dentate granule cell GABA-A receptors. J Neurosci. 1997; 17: 7532-40.

25. Mazarati AM, Baldwin RA, Sankar R, Wasterlain CG. Timedependent decrease in the effectiveness of antiepileptic drugs during the course of self-sustaining status epilepticus. Brain Res. 1998; 814: 179-85.

26. Bengzon J, Mohapel P, Ekdahl CT, Lindvall O. Neuronal apoptosis after brief and prolonged seizures. Prog Brain Res. 2002; 135: $111-19$.

27. Sloviter RS, Dean E, Sollas AL, Goodman JH. Apoptosis and necrosis induced in different hippocampal neuron populations by repetitive perforant path stimulation in the rat. J Comp Neurol. 1996; 366(3): 516-33.

28. Ekdahl CT, Mohapel P, Elmér E, Lindvall O. Caspase inhibitors increase short-term survival of progenitor-cell progeny in the adult rat dentate gyrus following status epilepticus. Eur J Neurosci. 2001; 14(6): 937-45.

29. Cendes F, Andermann F, Carpenter S, Zatorre RJ, Cashman NR. Temporal lobe epilepsy caused by domoic acid intoxication: evidence for glutamate receptor-mediated excitotoxicity in humans. Ann Neurol. 1995; 37: 123-6.

30. Alldredge BK, Gelb AM, Isaacs SM, et al. A comparison of lorazepam, diazepam, and placebo for the treatment of out-ofhospital status epilepticus. N Engl J Med. 2001; 345: 631-7.

31. Walker MC, Smith SJ, Shorvon SD. The intensive care treatment of convulsive status epilepticus in the UK: results of a national survey and recommendations. Anaesthesia. 1995; 50: 130-5.

32. Misra UK, Kalita J, Patel R. Sodium valproate vs. phenytoin in status epilepticus: a pilot study. Neurology. 2006 Jul 25; 67(2): 340-2.

33. Gilad R, Izkovitz N, Dabby R, et al. Treatment of status epilepticus and acute repetitive seizures with i.v. valproic acid vs phenytoin. Acta Neurol Scand. 2008; 118(5): 296-300.

34. Rossetti AO, Milligan TA, Vulliémoz S, Michaelides C, Bertschi M, Lee JW. A randomized trial for the treatment of refractory status epilepticus. Neurocrit Care. 2011; 14(1): 4-10.

35. Minicucci F, Muscas G, Perucca E, Capovilla G, Vigevano F, Tinuper P. Treatment of status epilepticus in adults: guidelines of the Italian League against Epilepsy. Epilepsia. 2006; 47 Suppl 5: 9-15.

36. Meierkord H, Boon P, Engelsen B, et al. EFNS guideline on the management of status epilepticus in adults. Eur J Neurol. 2010; 17(3): 348-55.

37. Robakis TK, Hirsch LJ. Literature review, case report, and expert discussion of prolonged refractory status epilepticus. Neurocrit Care. 2006; 4(1): 35-46.

38. Iyer VN, Hoel R, Rabinstein AA. Propofol infusion syndrome in patients with refractory status epilepticus: an 11-year clinical experience. Crit Care Med. 2009; 37(12): 3024-30.

39. Zarovnaya EL, Jobst BC, Harris BT. Propofol-associated fatal myocardial failure and rhabdomyolysis in an adult with status epilepticus. Epilepsia. 2007; 48(5): 1002-6.

40. Roberts RJ, Barletta JF, Fong JJ, et al. Incidence of propofol-related infusion syndrome in critically ill adults: a prospective, multicenter study. Crit Care. 2009; 13(5): R169.

41. Guitton C, Gabillet L, Latour P, et al. Propofol infusion syndrome during refractory status epilepticus in a young adult: successful ECMO resuscitation. Neurocrit Care. 2010 Aug;15(1):139-45.

42. Kassab MY, Lobeck IN, Majid A, Xie Y, Farooq MU. Blood pressure changes after intravenous fosphenytoin and levetiracetam in patients with acute cerebral symptoms. Epilepsy Res. 2009; 87(2-3): 268-71. 
43. Fischer JH, Patel TV, Fischer PA. Fosphenytoin: clinical pharmacokinetics and comparative advantages in the acute treatment of seizures. Clin Pharmacokin. 2003; 42(1): 33-58.

44. Perrott J, Murphy NG, Zed PJ. L-carnitine for acute valproic acid overdose: a systematic review of published cases. Ann Pharmacother. 2010; 44(7-8): 1287-93.

45. Wang $\mathrm{H}, \mathrm{Gao} \mathrm{J}$, Lassiter TF, et al. Levetiracetam is neuroprotective in murine models of closed head injury and subarachnoid hemorrhage. Neurocrit Care. 2006; 5(1): 71-8.

46. Eue S, Grumbt M, Müller M, Schulze A. Two years of experience in the treatment of status epilepticus with intravenous levetiracetam. Epilepsy Behav. 2009; 15(4): 467-9.

47. Berning S, Boesebeck F, van Baalen A, Kellinghaus C. Intravenous levetiracetam as treatment for status epilepticus. J Neurol. 2009; 256(10): 1634-42.

48. Wasterlain CG, Chen JW. Mechanistic and pharmacologic aspects of status epilepticus and its treatment with new antiepileptic drugs. Epilepsia. 2008; 49 Suppl 9: 63-73.

49. Fountain NB. Status epilepticus: risk factors and complications. Epilepsia. 2000;41 Suppl 2:S23-30.

50. Lundgren J, Smith ML, Blennow G, Siesjo BK. Hyperthermia aggravates and hypothermia ameliorates epileptic brain damage. Exp Brain Res. 1994; 99: 43-55.

51. Liu Z, Gatt A, Mikati M, Holmes GL. Effect of temperature on kainic acid-induced seizures. Brain Res. 1993; 631: 51-8.

52. Barry E, Hauser WA. Pleocytosis after status epilepticus. Arch Neurol. 1994; 51(2): 190-3.

53. Prokesch RC, Rimland D, Petrini JL Jr, Fein AB. Cerebrospinal fluid pleocytosis after seizures. South Med J. 1983; 76(3): 322-7.

54. Marik PE, Varon J. The management of status epilepticus. Chest. 2004; 126: 582-91.

55. Claassen J, Hirsch LJ, Emerson RG, et al. Continuous EEG monitoring and midazolam infusion for refractory nonconvulsive status epilepticus. Neurology. 2001; 57: 1036-42.

56. Lepelletier D, Roquilly A, Demeure dit latte D, et al. Retrospective analysis of the risk factors and pathogens associated with earlyonset ventilator-associated pneumonia in surgical-ICU headtrauma patients. J Neurosurg Anesthesiol. 2010; 22(1): 32-7.

57. Bertram EH, Lothman EW. NMDA receptor antagonists and limbic status epilepticus: a comparison with standard anticonvulsants. Epilepsy Res. 1990; 5: 177-84.

58. Mazarati AM, Wasterlain CG. N-methyl-D-asparate receptor antagonists abolish the maintenance phase of self-sustaining status epilepticus in rat. Neurosci Lett. 1999; 265: 187-90.

59. Hsieh CY, Sung PS, Tsai JJ, Huang CW. Terminating prolonged refractory status epilepticus using ketamine. Clin Neuropharmacol. 2010; 33(3): 165-7.

60. Fujikawa DG. Neuroprotective effect of ketamine administered after status epilepticus onset. Epilepsia. 1995; 36(2): 186-95.

61. Bleck TP, Quogg M, Nathan BR, Smith TL, Kapur J. Electroencephalographic effects of ketamine treatment for refractory status epilepticus. Epilepsia. 2002; 43: 282.

62. Ko YY, Jeong YH, Lim DY. Influence of ketamine on catecholamine secretion in the perfused rat adrenal medulla. Korean J Physiol Pharmacol. 2008; 12(3): 101-9.

63. Ben Yehuda Y, Watemberg N. Ketamine increases opening cerebrospinal pressure in children undergoing lumbar puncture. J Child Neurol. 2006; 21(6): 441-3.

64. Martin BS, Kapur J. A combination of ketamine and diazepam synergistically controls refractory status epilepticus induced by cholinergic stimulation. Epilepsia. 2008; 49(2): 248-55

65. Ubogu EE, Sagar SM, Lerner AJ, Maddux BN, Suarez JI, Werz MA. Ketamine for refractory status epilepticus: a case of possible ketamine-induced neurotoxicity. Epilepsy Behav. 2003; 4(1): 70-5.

66. Zou X, Patterson TA, Divine RL, et al. Prolonged exposure to ketamine increases neurodegeneration in the developing monkey brain. Int J Dev Neurosci. 2009; 27(7): 727-31.

67. Kofke WA, Young RS, Davis P, et al. Isoflurane for refractory status epilepticus: a clinical series. Anesthesiology. 1989; 71: 653-9.

68. Mirsattari SM, Sharpe MD, Young GB. Treatment of refractory status epilepticus with inhalational anesthetic agents isoflurane and desflurane. Arch Neurol. 2004; 61: 1254-9.
69. Ries CR, Puil E. Mechanism of action of anesthesia revealed by shunting actions of isoflurane on thalamocortical neurons. J Neurophysiol. 1999; 81: 1795-801.

70. Langmoen IA, Hegstad E, Berg-Johnsen J. An experimental study of the effect of isoflurane on epileptiform bursts. Epilepsy Res. 1992; 11: 153-7.

71. Franks NP, Lieb WR. Molecular and cellular mechanisms of general anesthesia. Nature. 1994; 367: 607-14.

72. Bernard SA, Gray TW, Buist MD, Jones BM, Silvester W, Gutteridge G. Treatment of comatose survivors of out-ofhospital cardiac arrest with induced hypothermia. N Engl J Med. 2002 Feb 21; 346(8): 557-63.

73. Hypothermia after Cardiac Arrest Study Group. Mild therapeutic hypothermia to improve the neurologic outcome after cardiac arrest. N Engl J Med. 2002 Feb 21; 346(8): 549-56.

74. Liu Z, Gatt A, Mikati M, Holmes GL. Effect of temperature on kainic acid-induced seizures. Brain Res. 1993;631(1):51-8.

75. Schmitt FC, Buchheim K, Meierkord H, Holtkamp M. Anticonvulsant properties of hypothermia in experimental status epilepticus. Neurobiol Dis. 2006; 23(3): 689-96.

76. Maeda T, Hashizume K, Tanaka T. Effect of hypothermia on kainic acid-induced limbic seizures: an electroencephalographic and 14C-deoxyglucose autoradiographic study. Brain Res. 1999; 818 (2): 228-35.

77. Corry JJ, Dhar R, Murphy T, Diringer MN. Hypothermia for refractory status epilepticus. Neurocrit Care. 2008; 9(2): 189-97.

78. Ng YT, Bristol RE, Schrader DV, Smith KA. The role of neurosurgery in status epilepticus. Neurocrit Care. 2007; 7(1): 86-91

79. Schrader DV, Steinbok P, Connolly MB. Urgent resective surgery for refractory status epilepticus. Epilepsia. 2006; 47(S4): 149.

80. Costello DJ, Simon MV, Eskandar EN, et al. Efficacy of surgical treatment of de novo, adult-onset, cryptogenic, refractory focal status epilepticus. Arch Neurol. 2006; 63: 895-901.

81. Molyneux PD, Barker RA, Thom M, van Paesschen W, Harkness WF, Duncan JS. Successful treatment of intractable epilepsia partialis continua with multiple subpial transections. J Neurol Neurosurg Psychiatry. 1998; 65: 137-8.

82. D'Giano CH, Del CG, Pomata H, Rabinowicz. Treatment of refractory partial status epilepticus with multiple subpial transection: case report. Seizure. 2001; 10: 382-5.

83. Bristol RE, Gore P, Treiman D, Smith KA. Resolution of status epilepticus after subdural grid recording and multiple subpial transections. Barrow Quarterly. 2006; 22: 8-11.

84. Ng YT, Kim HL, Wheless JW. Successful neurosurgical treatment of childhood complex partial status epilepticus by focal resection. Epilepsia. 2003; 44: 468-71.

85. Duane DC, Ng YT, Rekate HL, Chung S, Bodensteiner JB, Kerrigan JF. Treatment of refractory status epilepticus with hemispherectomy. Epilepsia. 2004; 45: 1001-4.

86. Winston KR, Levisohn P, Miller BR, Freeman J. Vagal nerve stimulation for status epilepticus. Pediatr Neurosurg. 2001; 34: $190-2$.

87. Patwardhan RV, Dellabadia J Jr, Rashidi M, Grier L, Nanda A. Control of refractory status epilepticus precipitated by anticonvulsant withdrawal using left vagal nerve stimulation: a case report. Surg Neurol. 2005; 64: 170-3.

88. Carrasco G, Palomar M, Rovira R. Electroconvulsive therapy for status epilepticus. Ann Intern Med. 1997; 127: 247-8.

89. Griesemer DA, Kellner CH, Beale MD, Smith GM. Electroconvulsive therapy for treatment of intractable seizures. Initial findings in two children. Neurology. 1997; 49: 1389-92.

90. Lisanby SH, Bazil CW, Resor SR, Nobler MS, Finck DA, Sackeim HA. ECT in the treatment of status epilepticus. J ECT. 2001; 17: $210-15$

91. Cline JS, Roos K. Treatment of status epilepticus with electroconvulsive therapy. J ECT. 2007; 23: 30-2.

92. Kamel H, Cornes SB, Hegde M, Hall SE, Josephson SA. Electroconvulsive therapy for refractory status epilepticus: a case series. Neurocrit Care. 2010; 12(2): 204-10.

93. Sackeim HA. The anticonvulsant hypothesis of the mechanisms of action of ECT: current status. J ECT. 1999; 15(1): 5-26. 
94. Claassen J, Mayer SA, Kowalski RG, Emerson RG, Hirsch LJ. Detection of electrographic seizures with continuous EEG monitoring in critically ill patients. Neurology. 2004; 62(10): 1743-8.

95. Young GB, Jordan KG, Doig GS. An assessment of nonconvulsive seizures in the intensive care unit using continuous EEG monitoring: an investigation of variables associated with mortality. Neurology. 1996; 47(1): 83-9.

96. Young GB, Jordan KG. Do nonconvulsive seizures damage the brain? - Yes. Arch Neurol. 1998; 55(1): 117-19.

97. Brandt C, Glien M, Potschka H, Volk H, Löscher W. Epileptogenesis and neuropathology after different types of status epilepticus induced by prolonged electrical stimulation of the basolateral amygdala in rats. Epilepsy Res. 2003; 55(1-2): 83-103.

98. Bengzon J, Mohapel P, Ekdahl CT, Lindvall O. Neuronal apoptosis after brief and prolonged seizures. Prog Brain Res. 2002; 135 : $111-19$

99. Mikulecká A, Krsek P, Hlinák Z, Druga R, Mares P. Nonconvulsive status epilepticus in rats: impaired responsiveness to exteroceptive stimuli. Behav Brain Res. 2000; 117(1-2): 29-39.

100. Nevander G, Ingvar M, Auer R, Siesjö BK. Status epilepticus in well-oxygenated rats causes neuronal necrosis. Ann Neurol. 1985; 18(3): 281-90.

101.Krsek P, Mikulecká A, Druga R, et al. Long-term behavioral and morphological consequences of nonconvulsive status epilepticus in rats. Epilepsy Behav. 2004; 5(2): 180-91.

102. Young GB, Campbell VC. EEG monitoring in the intensive care unit: pitfalls and caveats. J Clin Neurophysiol. 1999; 16(1): 40-5.

103. Sigl JC, Chamoun NG. An introduction to bispectral analysis for the electroencephalogram. J Clin Monit. 1994; 10(6): 392-404.

104. Hasselman K, Munk W, MacDonald G. Bispectra of ocean waves. In: Rosenblatt M, editor. Time series analysis. New York: John Wiley \& Sons; 1963. p. 125-39.

105. Haubrich RA. Earth noise, 5 to 500 millicycles per second. J Geophys Res. 1965; 70: 1415-27.

106. Tallach RE, Ball DR, Jefferson P. Monitoring seizures with the Bispectral index. Anaesthesia. 2004; 59(10): 1033-4.

107. Dahaba AA, Liu DW, Metzler H. Bispectral index (BIS) monitoring of acute encephalitis with refractory, repetitive partial seizures (AERRPS). Minerva Anestesiol. 2010; 76(4): 298-301.

108. Bridgers SL, Ebersole JS. EEG outside the hairline: detection of epileptiform abnormalities. Neurology. 1988; 38(1): 146-9.

109. Young GB, Sharpe MD, Savard M, Al Thenayan E, Norton L, Davies-Schinkel C. Seizure detection with a commercially available bedside EEG monitor and the subhairline montage. Neurocrit Care. 2009; 11(3): 411-16.

110. Karakis I, Montouris GD, Otis JA, Douglass LM, Jonas R, VelezRuiz N. A quick and reliable EEG montage for the detection of seizures in the critical care setting. J Clin Neurophysiol. 2010; 27(2): 100-5.

111. Task Force of the Canadian Society of Clinical Neurophysiologists. Minimal standards for electroencephalography in Canada. Can J Neurol Sci. 2002; 29(3): 216-20.

112. Boulanger JM, Deacon C, Lécuyer D, Gosselin S, Reiher J. Triphasic waves versus nonconvulsive status epilepticus: EEG distinction. Can J Neurol Sci. 2006; 33(2): 175-80.

113. Dalmau J, Tüzün E, Wu HY, et al. Paraneoplastic anti-N-methyl-Daspartate receptor encephalitis associated with ovarian teratoma. Ann Neurol. 2007; 61(1): 25-36.

114. Thieben MJ, Lennon VA, Boeve BF, et al. Potentially reversible autoimmune limbic encephalitis with neuronal potassium channel antibody. Neurology. 2004; 62(7): 1177-82.

115. Wall CJ, Kendall EJ, Obenaus A. Rapid alterations in diffusionweighted images with anatomic correlates in a rodent model of status epilepticus. AJNR Am J Neuroradiol. 2000; 21(10): 1841-52.
116. Engelhorn T, Hufnagel A, Weise J, Baehr M, Doerfler A. Monitoring of acute generalized status epilepticus using multilocal diffusion MR imaging: early prediction of regional neuronal damage. AJNR Am J Neuroradiol. 2007; 28(2): 321-7.

117. Katramados AM, Burdette D, Patel SC, Schultz LR, Gaddam S, Mitsias PD. Periictal diffusion abnormalities of the thalamus in partial status epilepticus. Epilepsia. 2009; 50: 265-75.

118. Boyd JG, Taylor S, Rossiter JP, Islam O, Spiller A, Brunet DG. New-onset refractory status epilepticus with restricted DWI and neuronophagia in the pulvinar. Neurology. 2010; 74(12): 1003-5.

119. Milligan TA, Zamani A, Bromfield E. Frequency and patterns of MRI abnormalities due to status epilepticus. Seizure. 2009; 18 (2): $104-8$

120.Di Bonaventura C, Bonini F, Fattouch J, et al. Diffusion-weighted magnetic resonance imaging in patients with partial status epilepticus. Epilepsia. 2009; 50 Suppl 1: 45-52.

121. Grommes C, Oghlakian R, Blackham KA, De Georgia MA. Corpus callosum dysgenesis limits MRI changes to one hemisphere in status epilepticus. Neurology. 2009; 72(10): 942.

122. Canas N, Soares P, Calado S, Pestana R, Ribeiro C, Vale J. Pathophysiology and long-term outcome of reversible tumorlike lesions induced by presenting status epilepticus. J Neuroimaging. 2010; 20(2): 169-74

123. van Eijsden P, Otte WM, van der Hel WS, et al. In vivo diffusion tensor imaging and ex vivo histologic characterization of white matter pathology in a post-status epilepticus model of temporal lobe epilepsy. Epilepsia. 2011; 52(4): 841-5.

124. Kawahara I, Tsutsumi K, Hirose M, Matsuo Y, Yokoyama H. Transient abnormalities associated with status epilepticus on diffusion-weighted MR imaging. No To Shinkei. 2004; 56(4): 333-8.

125. Urbach H, Soeder BM, Jeub M, Klockgether T, Meyer B, Bien CG. Serial MRI of limbic encephalitis. Neuroradiology. 2006; 48(6): 380-6.

126. Bonita R, Beaglehole R. "Modification of Rankin Scale: Recovery of motor function after stroke." Stroke. 1988; 19(12): 1497-500.

127. Jennett B, Bond M. Assessment of outcome after severe brain damage. Lancet. 1975; 1(7905): 480-4.

128. Treiman DM, Delgado-Escueta AV, Clark MA. Impairment of memory following complex partial status epilepticus. Neurology. 1981; 31: 109.

129. Kitagawa T, Takahashi K, Matsushima K, Kawahara R. A case of prolonged confusion after temporal lobe psychomotor status. Folia Psychiatr Neurol. 1989; 33: 279-84.

130. Adachi N, Kanemoto K, Muramatsu R, et al. Intellectual prognosis of status epilepticus in adult epilepsy patients: analysis with Wechsler Adult Intelligence Scale-revised. Epilepsia. 2005; 46 (9): 1502-9.

131. Wilder-Smith EP, Lim EC, Teoh HL, et al. The NORSE (new-onset refractory status epilepticus) syndrome: defining a disease entity. Ann Acad Med. Singapore. 2005; 34(7): 417-20.

132. Van Lierde I, Van Paesschen W, Dupont P, Maes A, Sciot R. De novo cryptogenic refractory multifocal febrile status epilepticus in the young adult: a review of six cases. Acta Neurol Belg. 2003; 103(2): 88-94.

133. Hoerth MT, Sirven JI, Drazkowski JF, Noe KH. Malignant status epilepticus syndrome: refractory idiopathic status epilepticus. Epilepsia. 2007; 48(S6): P012.

134. Costello DJ, Kilbride RD, Cole AJ. Cryptogenic New Onset Refractory Status Epilepticus (NORSE) in adults-Infectious or not? J Neurol Sci. 2009; 277(1-2): 26-31.

135. Kanter IC, Huttner HB, Staykov D, et al. Cyclophosphamide for anti-GAD antibody-positive refractory status epilepticus. Epilepsia. 2008; 49(5): 914-20. Epub 2007 Dec 28.

136. Shorvon S, Tan R. Uncommon causes of status epilepticus. Epilepsia. 2009; 50 Suppl 12: 61-3. 